\title{
Eosinophilic leukaemia terminating with an encephalopathy
}

\author{
G. M. YUILL \\ M.B., M.R.C.P., B.Sc.
}

\author{
R. G. LASCELles \\ M.D., M.R.C.P., D.P.M.
}

\author{
C. Scholtz \\ M.B., B.S., F.R.C.P.A.
}

Departments of Clinical Neurology and Neuropathology, Manchester University

\begin{abstract}
Summary
A 52-year-old man developed an illness which lasted for 2 years until its fatal termination. It comprised in chronological order: mild asthma, skin irritation, mature eosinophilia in the peripheral blood, and finally an encephalopathy. The diagnostic problem of distinguishing between eosinophilic leukaemia and an eosinophilic leukaemoid reaction is discussed. The cause of the encephalopathy was discovered at autopsy to be a widespread intravascular thrombotic process. The Aluestion of future possible therapy is discussed.
\end{abstract}

\section{Case history}

A 52-year-old male presented with an illness of 12 months' duration, comprising in chronological order: irritation of the skin, rhinorrhoea, mild wheezing, and finally painless enlargement of the glands in the neck. On examination the only abnormality was a firm painless enlargement of the supraclavicular, and submandibular glands. The clinical diagnoses considered were Hodgkin's disease, or collagen disease. The following investigations were performed.

The urine was normal. The blood haemoglobin was $16 \mathrm{~g} / 100 \mathrm{ml}$, blood white cell count $18,000 / \mathrm{mm}^{3}$. Differential white cell count, neutrophils $50 \%$, lymphocytes $8 \%$, monocytes $3 \%$, eosinophils $38 \%$, basophils $1 \%$, ESR (Wintrobe) $9 \mathrm{~mm}$ in the first hour. A gland biopsy was taken from the right side of the neck. It showed a non-specific inflammatory reaction with significant eosinophilic infiltration. A sternal marrow was normal except that there was an increase in eosinophils which comprised $23.5 \%$ of the total cell population. There was no parasite infection in the stools.

He was treated with oral prednisolone $10 \mathrm{mg}$ three times daily, and the lymphadenopathy resolved over 2 months. The dosage of prednisolone was slowly reduced. The sequential changes in the blood count are shown in Fig. 1. After 8 months he complained of nasal obstruction. There was no local nasal

Correspondence: Dr G. M. Yuill, The department of Neurology, Manchester Royal Infirmary, Oxford Road, Manchester.

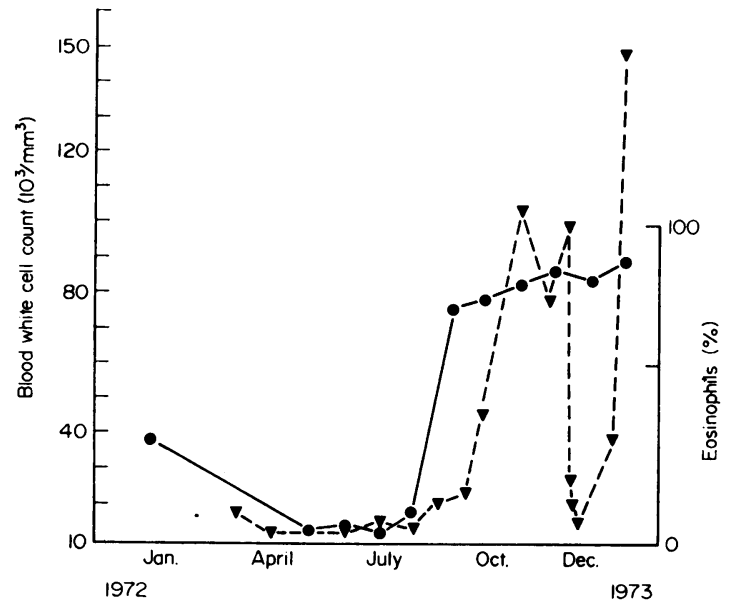

FIG. 1. Graph showing the patient's bloodcount during the course of his illness. eosinophils as $\%$ of total white cell count; $\nabla$, total white cell count.

abnormality. X-rays showed mild opacification of the frontal sinuses. The spleen was now enlarged 2 finger breadths below the costal margin. Further investigations were as follows.

Blood haemoglobin $13.6 \mathrm{~g} / 100 \mathrm{ml}$, blood white cell count $86,000 / \mathrm{mm}^{3}$; differential white cell countneutrophils $9 \%$, lymphocytes $3 \%$, monocytes $1 \%$, eosinophils $87 \%$. The ESR (Wintrobe) was $13 \mathrm{~mm}$ in the first hour. Serum albumen $2.9 \mathrm{~g} / 100 \mathrm{ml}$, serum globulin $4.2 \mathrm{~g} / 100 \mathrm{ml}$; serum protein electrophoresis showed a slight increase in alpha 1 and alpha 2 globulin, and a moderate diffuse increase in gamma globulin. Serum alkaline phosphatase $22.5 \mathrm{King}$ Armstrong units, serum uric acid $6.5 \mathrm{~g} / 100 \mathrm{ml}$. The serum Vitamin $B_{12}$ was $200 \mathrm{pg} / \mathrm{ml}$, serum folic acid $0.6 \mathrm{ng} / \mathrm{ml}$. The alkaline phosphatase score was 114 (raised) in the neutrophil polymorphs, and was nil in the eosinophilic polymorphs. The blood urea was 36 $\mathrm{mg} / 100 \mathrm{ml}$; the serum electrolytes were sodium 134 $\mathrm{mEq} / \mathrm{l}$, potassium $4.8 \mathrm{mEq} / \mathrm{l}$, and chloride $101 \mathrm{mEq} / \mathrm{l}$. The liver function tests were: thymol turbidity $2 \cdot 0$, SGOT 14, SGPT 11, and serum bilirubin $1.0 \mathrm{mg} / 100$ 
ml. Again no parasites or ova could be found in the stools. The sheep cell agglutination test was negative. The bleeding time was 1 min (normal 2-5), the prothrombin time $13 \mathrm{sec}$ (control $12 \mathrm{sec}$ ). The plasma clotting time and the thrombin clotting time were both normal. The chest X-ray was normal. The liver biopsy showed a normal liver architecture, with a minor degree of infiltration by mature eosinophils. The philadelphia chromosome was absent.

The diagnosis was felt to be an atypical form of polyarteritis nodosa, or possibly Wegener's granulomatosis. He was treated with oral cyclophosphamide $100 \mathrm{mg}$ daily, prednisolone $120 \mathrm{mg}$ orally, and septrin 1 tablet daily (sulphamethoxazole $400 \mathrm{mg}$, trimethoprim $80 \mathrm{mg}$ ). The blood white cell count fell and the dosage of prednisolone was reduced over 2 weeks to $30 \mathrm{mg}$ orally daily, and he was discharged. Two weeks later he developed general malaise, cough, and a temperature of $100 \cdot 4^{\circ} \mathrm{F}$. He was readmitted. The blood pressure was $110 / 70 \mathrm{mmHg}$, the pulse $120 / \mathrm{min}$ and regular. There was a mild bilateral tonsillar lymphadenopathy. The liver was palpable 2 finger breadths and the spleen 1 finger breadth below the costal margin. There was no abnormality in the heart, lungs, nervous system, or remaining gland fields. Four days after this admission he developed herpetic cold sores on the lips. Ten days after admission he became confused, restless, and incontinent of urine. A presumptive diagnosis of herpes simplex encephalitis was made and he was transferred to the neurological unit at Manchester Royal Infirmary. He developed right basal pneumonic consolidation, and lapsed into coma associated with decerebrate rigidity. There was no neck stiffness. The fundi were normal. $\mathrm{He}$ was treated with intravenous hydrocortisone, ampicillin, cloxacillin, and $250 \mathrm{mg}$ of cytosine arabinoside. Over the next $24 \mathrm{hr}$ both pupils became fixed and dilated, respiration became fast and shallow, and he died. The cerebrospinal fluid was clear, colourless, and under normal pressure. It contained 370 white cells, polymorphs $30 \%$ and lymphocytes $70 \%$. The protein was $30 \mathrm{mg} / 100 \mathrm{ml}$ and the glucose $94 \mathrm{mg} / 100$ $\mathrm{ml}$. Gram and Ziehl Neelson stains were negative and no bacteria were cultured. Attempts to culture viruses from the cerebrospinal fluid were made in the following media: Monkey kidney cells, Hela cells, HEp 2 cells, human amnion and human embryo fibroblast (diploid) cells. No virus was isolated.

\section{Autopsy findings (C.S.)}

There was no external evidence of a haemorrhagic diathesis. The main findings were in the abdomen. The spleen was enlarged and on sectioning had a pink homogenous appearance and weighed $1500 \mathrm{~g}$. The liver was enlarged and had a pale grey cut surface. It weighed $2470 \mathrm{~g}$. There was enlargement of the para-aortic lymph nodes. The upper pole of the left kidney contained a haemorrhagic yellow tumour, the appearance of which was typical of a Grawitz tumour. There was bilateral pulmonary oedema. Small thrombi were noted in the pulmonary arterioles. There was no pathology in the upper respiratory tract. The heart was not enlarged and weighed $345 \mathrm{~g}$ and within it were ante-mortem thrombi attached to the trabeculae carnae under the mitral valve over an area $2 \times 2 \mathrm{~cm}$. Examination of the brain showed a venous thrombosis in the right parieto-occipital region with no obvious underlying infarction. Examination of the brain and spinal cord failed to reveal any macroscopic pathology.

Microscopic histological examination revealed widespread infiltration of tissues, by large numbers of mature eosinophils which were seen in the haemopoietic and non-haemopoietic organs. The femoral bone marrow contained normal erythropoietic elements and normal megakaryocytes, along with

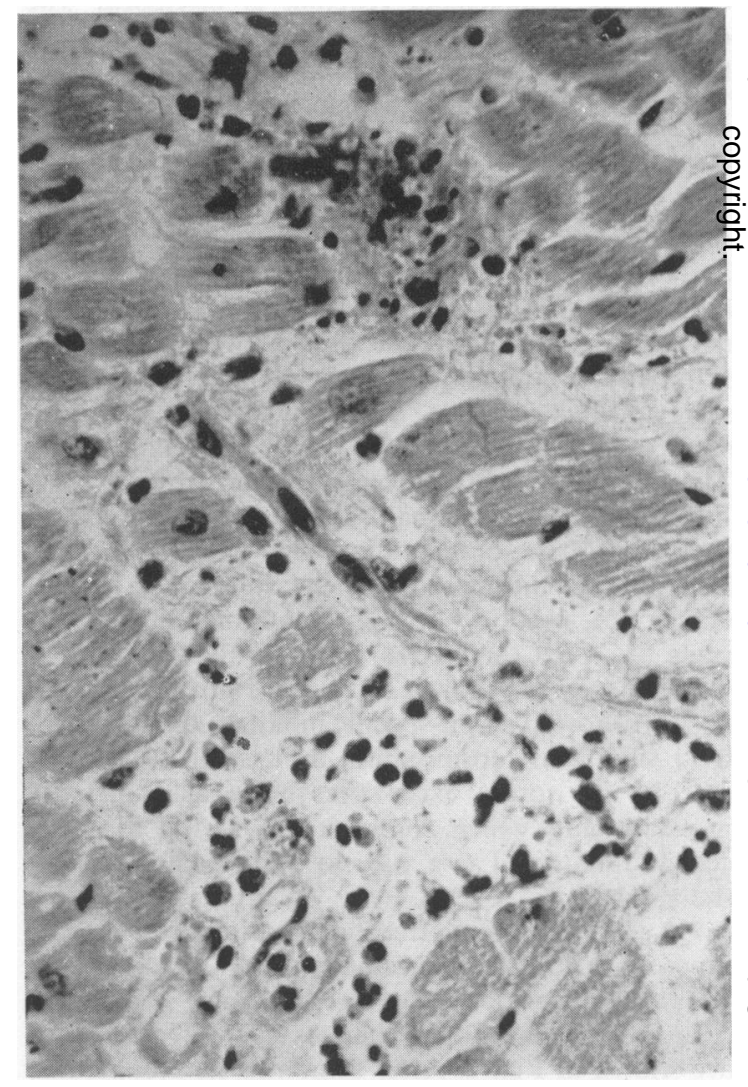

FIG. 2. A focal area of myocardial necrosis surrounded by macrophages. Eosinophilic polymorphs are seen infiltrating the surrounding myocardium. Haematoxylin and eosin $(\times 250)$. 


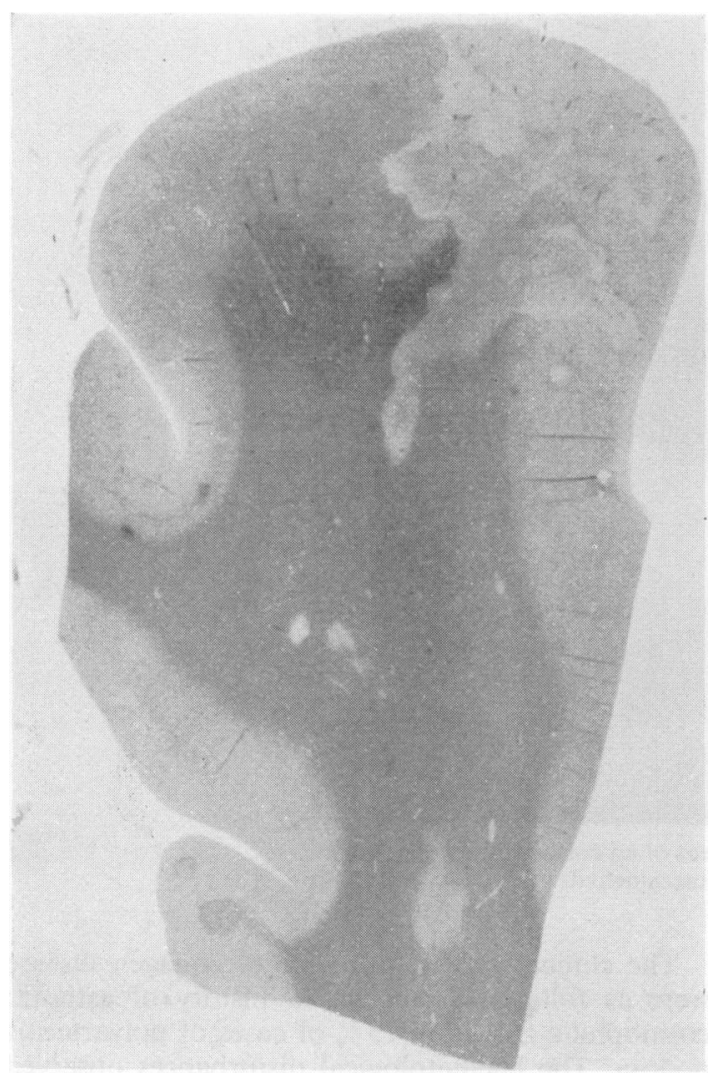

Fig. 3. A low power section of cerebral cortex showing an infarct of the grey and white matter. Haematoxylin and $\operatorname{cosin}(\times 10)$.

large numbers of mature eosinophils and their precursors, mainly metamyelocytes and only a few blast cells. The lymph nodes had lost their germinal centres which had been replaced by mature eosinophils. The spleen similarly consisted of sheets of mature eosinophils almost obliterating the normal architecture. The sections of the heart confirmed the presence of an ante-mortem thrombus. Large numbers of eosinophils were present on the left ventricular myocardium particularly. There were focal areas of myocardial fibre necrosis with evidence of macrophage activity (Fig. 2). Some of these areas also contained eosinophils. Adjacent to the areas of myocardial necrosis were arteries whose lumen contained thrombi, and whose walls were thickened owing to fibrosis. The elastic laminae were intact and there was no evidence of an arteritis.

The lungs showed pulmonary oedema and abundant eosinophils in the fluid and interstitial tissues. Some arterioles contained ante-mortem thrombi and the walls were thickened by an increase in the amount of fibrous tissue. Similarly arterioles in the kidneys

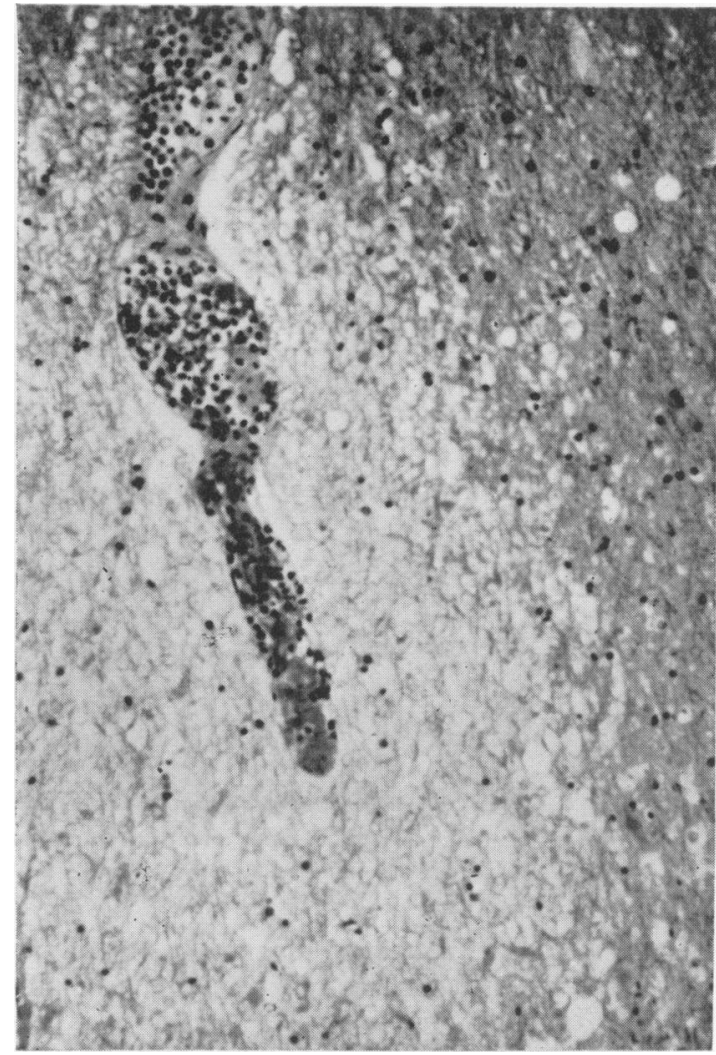

FIg. 4. Thrombus in a cerebral capillary, consisting predominantly of mature eosinophils. There is oedema of the surrounding brain. Haematoxylin and eosin $(\times 100)$.

contained thrombi, focal collections of eosinophil infiltrates and the walls of the vessels were thickened by intimal fibrosis. The tumour in the kidney was a clear cell adenocarcinoma. The liver contained eosinophils in both the sinusoids and the portal tracts, but was otherwise normal.

The brain sections revealed infarcts of the grey and white matter in both cerebral hemispheres, see Fig. 3. These were triangular in shape and were up to $1 \mathrm{~cm}$ along each edge. There were thrombi in the vessels related to them (Fig. 4). The vessels were not thickened; most contained large numbers of eosinophils in the lumen. Only one haemorrhagic infarct was noted.

Electromicroscopy of a mature eosinophil from the brain revealed a helical virus-like structure in tho nucleus similar to murine leukaemia virus (Fig. 5).

\section{Discussion}

There have been numerous descriptions of socalled eosinophilic leukaemia in the literature. Some 


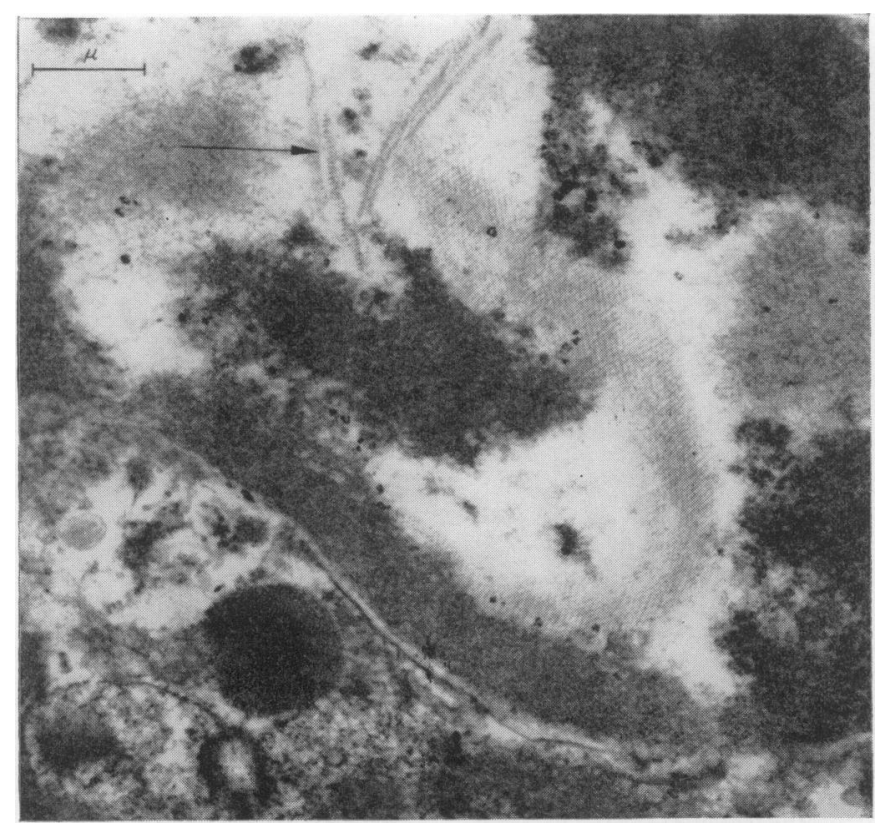

FIG. 5. Electron microscopy. The nucleus of an eosinophilic polymorph containing a helical viral structure, Gluteraldehyde-osmic acid fixed, stained with Reynolds lead citrate stain.

do not fulfil the necessary diagnostic criteria required for classification as leukaemias, i.e. a pronounced blood eosinophilia with an excess of immature forms in the peripheral blood and the bone marrow; more than $5 \%$ blast cell types in the bone marrow, tissue infiltration by immature cells of predominantly eosinophilic types, anaemia, thrombocytopenia and a haemorrhagic tendency (Bentley et al., 1961; Rickles and Miller, 1972). De Gruchy (1970) comments that the eosinophils are commonly of the mature type, that the philadelphia chromosome has occasionally been demonstrated and that endomyocardial fibrosis with mural thrombosis is a fairly common complication, which often causes cardiac failure and death. He also comments on the occasional difficulty which may arise in distinguishing between eosinophilic leukaemia in which the cells are relatively mature and some cases of secondary eosinophilia. Some authors doubt the existence of eosinophilic leukaemia as a distinct disease entity (Odeberg, 1965).

The points in favour of a leukaemic process in our case were the high white cell count, the lymphadenopathy, the terminal hepato-splenomegaly, the low eosinophilic polymorph alkaline phosphatase score and the infiltration of tissues by eosinophilic polymorphs. However, investigation revealed a striking absence of immature eosinophils, or other immature white cells, no depression of the platelet count, no anaemia, and no bleeding tendency.
The clinical points in favour of collagen disease were as follows. There was a history of asthma; eosinophilia is seen in $25 \%$ of cases of polyarteritis nodosa. The haematological disturbances observed were those of a leukaemoid reaction as described by De Gruchy (1970). There was reversal of the serum protein ratio with hyperglobulinaemia, and electrophoresis showed this was mainly due to a diffuse rise in alpha globulin. On the other hand his ESR was never significantly raised, he was persistently normotensive, had no proteinuria, and did not become uraemic.

Eosinophilia does occur in numerous other conditions, of which the ones following are germane to our case. There were no symptoms of gastrointestinal parasite infestation, and no organisms were seen in the stools. In Loeffler's syndrome transitory opacities are seen on chest X-rays, there is frequently an Ascaris lumbricoides infection, and the condition usually settles in 4-6 weeks. This is clearly in marked contrast to our own case, who also was mildly asthmatic, a feature not seen in Loeffler's syndrome.

During life we thought that his encephalopathy was due to a viral encephalitis, as he had herpetic cold sores on the lips and was on treatment with a cytotoxic agent and steroids which would predispose him to a virus infection. An alternative clinical explanation considered was that this represented a vasculitis involving the cerebral arterioles. This was conjectural, as there was no clinical evidence of 
vasculitis elsewhere. The transient but definite improvement in response to steroids and cyclophosphamides cannot be adduced as evidence in favour of either collagen disease or eosinophilic leukaemia. In summary, the clinical aspects of the case are not those of a leukaemic process. However, when one attempts to classify the process, it can be seen that we have a non-specific syndrome which could be either a collagen disease, or an eosinophilic leukaemoid reaction.

The findings on histological examination do not fulfil the necessary diagnostic criteria for a leukaemic process. On the other hand there were very few features to substantiate the presence of a collagen disease. There was slight thickening of the walls of the pulmonary and renal arteries, but no arteritis and there were the small necrotic foci in the myocardium. There were no features to support the possibilities of polyarteritis nodosa, lupus erythematosis, or Wegener's granulomatosis. The clinical diagnostic difficulty is to some extent paralleled in the pathological findings.

The autopsy produced several quite unexpected findings. Firstly, there was ante-mortem endocardial thrombosis in the left ventricle. Secondly, in the lungs and kidneys thrombi were found in many small arteries. Thirdly, in the brain there were numerous thrombosed vessels with areas of focal necrosis adjoining them, but there was no evidence of a viral encephalitis. Finally there was an asymptomatic Grawitz tumour in the kidney.

The autopsy answers several questions. The final encephalopathic illness was due to a cerebrovascular thrombotic disorder, not to a virus infection, nor to a vasculitis. The presence of thrombus in the pulmonary arteries, left ventricle, renal and cerebral arteries suggests that a generalized thrombotic tendency was present.

The relevance of the Grawitz tumour is conjectural. Such tumours are commonly found at autopsy when there had been no clinical suspicion of their presence. We have not found a Grawitz tumour reported in the literature in association with eosinophilic leukaemia. We feel that this tumour may be an incidental finding here as Grawitz tumours are common, and the eosinophilic leukaemia syndrome is rare.

Clinical involvement of the central nervous system has been documented in a few cases. Faddel et al. (1957) described a 27-year-old male who amongst other symptoms complained of attacks of delusions and dizziness. This could have been related to thrombo-embolic disease as he had mural thrombi in both ventricles. Bentley et al. (1961) described a 5-year-old boy who had a week's history of fever, petechial rash, hepatosplenomegaly and lymphadenopathy and went into coma. In this case extensive left ventricular mural thrombus was present. Bentley also described necrotic foci in the myocardium similar to the lesions we have seen.

Gardner-Thorpe et al. (1971) described four male patients who developed headache, parietal lobe syndromes, dysphasia, pyramidal signs and disturbance of eye movement, associated with a mature eosinophilic leukocytosis of the peripheral blood. Autopsy examination in two showed left ventricular mural thrombi and widespread arteriolar occlusion.

These cases are clearly similar to our case. They differ, however, in several respects, for which we have no explanation. Their neurological symptoms were relatively chronic, all four had cardiac gallop rhythms, and two died in congestive cardiac failure. This contrasts with our case, presenting with lymphadenopathy, and terminating with a short lived fatal encephalopathy.

Nordlander (1951) described a 44-year-old man who had definite eosinophilic leukaemia. Terminally he developed anaesthesiae of the left side of the face and infiltration of the skin and retina. Autopsy revealed widespread eosinophilic infiltration of many organs, including the body of the left gasserian ganglion. It can be seen that the pathology in our case is similar to other previous reports where thrombotic disease has been present. During life there were no clinical features to suggest that intravascular coagulation was present, or that a micro-angiopathic haemolytic anaemia existed. Detailed clotting factor studies were unfortunately not undertaken, but his bleeding and clotting times, plasma and thrombin clotting times were normal, and there was no bleeding tendency. The only point of note was that his platelet count (taken within $24 \mathrm{hr}$ of death) was $47,000 / \mathrm{mm}^{3}$. This would have been consistent with the presence of intravascular coagulation. Some degree of intra-vascular fibrin deposition is seen in the haemolytic uraemic syndrome; but our patient was normotensive and his blood urea was normal. There are now several reports of the efficacy of heparinization in treating the haemolytic uraemic syndrome, as well as in the successful treatment of the consumption coagulopathies. Had we been able to make the diagnosis in life it might have been worthwhile heparinizing him, in the hope of preventing widespread thrombosis. We would propose that further cases of this syndrome should be investigated with a view to detecting intravascular coagulation at the earliest possible moment and that once discovered it should be treated with heparin. The incidence of this terminal complication is unknown as there are few detailed neuropathological reports in the literature.

\section{Conclusions}

In conclusion we feel that this case-and others 
like it -fall somewhat across the diagnostic boundaries lying between genuine eosinophilic leukaemia, and eosinophilic collagen disease. These two conditions may be extremes of a single spectrum caused by a basic single underlying cause as yet unknown. We would propose that a descriptive title should be used to avoid unintentional categorization, such as idiopathic eosinophilic leukaemoid reaction. The relation of the terminal diffuse intravascular thrombotic process to the initial disease process is obscure.

The role, if any, of the intracellular virus-like particle, seen only in the nucleus of one eosinophil is quite unknown. There were no pathological features of encephalitis. As there was no lymphatic vasculitis, one cannot postulate that a sensitivity reaction occurring between the agent and antibodies against it was causing local fibrin deposition and intra-vascular coagulation. It may be present in the similar uncertain role played by the polyoma virus in the progressive multifocal leukoencephalopathy seen associated with Hodgkin's disease. We feel unjustified in drawing any conclusions on the strength of one isolated observation.

\section{Acknowledgment}

We should like to thank Dr C. D. R. Pengelly, Consultant Physician at Altrincham General Hospital, for referring this patient.

\section{References}

Bentley, H.P., Reardon, A.E., Knoedler, J.P. \& Krivit, W. (1961) Eosinophilic leukaemia; report of a case with review and classification. The American Journal of Medicine, 30, 310.

De Gruchy, G.C. (1970) Clinical Haematology in Medical Practice, p. 456. Third Edition. Blackwell Scientific Publications, Oxford.

ENgfeldt, B. \& Zetterström, R. (1956) Disseminated eosinophilic collagen disease. A clinical and pathological study of a clinical entity related to Loeffler's syndrome. Acta Medica Scandinavica, 153 (5), 337.

Faddell, E.J., Crone, R.I., Leonard, M.E. \& Altamirano, M.D. (1957) Eosinophilic leukaemia. Archives of Internal Medicine, 99, 819.

Gardner-Thorpe, C., Harriman, D.G.F., Parsons, M. \& Rudge, P. (1971) Loeffler's eosinophilic endocarditis with Balint's syndrome (optic ataxia and paralysis of visual fixation). Quarterly Journal of Medicine, 158, 249.

Nordlander, N.B. (1951) Eosinophilic leukaemia infiltrating the gasserian ganglion. Acta Medica Scandinavica, 139 (2), 146 .

ODEBerg, B. (1965) Eosinophilic leukaemia and disseminated eosinophilic collagen disease - a disease entity. Acta Medica Scandinavica, 177, 129.

Rickles, F.R. \& Miller, D.R. (1972) Eosinophilic leukaemoid reactions. Report of a case and its relationship to eosinophilic leukaemia and review of the paediatric literature. Journal of Paediatrics, 80, 418.

\title{
Treatment of pulmonary tuberculosis in a patient on maintenance haemodialysis
}

\author{
F. W. SMITH \\ M.B., Ch.B. \\ Medical Renal Unit, Aberdeen Royal Infirmary
}

\author{
G. R. D. CAtTo \\ M.B., M.R.C.P.(U.K.) \\ University of Aberdeen
}

\author{
M. MACLeOD \\ M.D., F.R.C.P.E. \\ University of Aberdeen
}

\begin{abstract}
Summary
A case of pulmonary tuberculosis in a patient on maintenance haemodialysis is reported. A 37-year-old man who had received intermittent haemodialysis for 5 years, developed pulmonary tuberculosis which was treated initially with isoniazid, sodium aminosalicylate (PAS) and rifampicin. Isoniazid and PAS were discontinued and treatment continued with rifampicin alone. One year later, the patient is well, has no evidence of active tuberculosis and undertakes his own dialysis at home.
\end{abstract}

\section{Introduction}

Pulmonary tuberculosis is a serious and not uncommon complication of chronic renal failure treated by maintenance haemodialysis (Brunner et al., 1972). Adequate therapy for the condition is difficult to assess clinically as the major therapeutic agents, including streptomycin, sodium aminosalicylate (PAS), isoniazid and ethambutol, are normally excreted in the urine (Welch, 1954) and produce important toxic effects if blood levels become elevated. Thus, in oliguric or anuric patients, safe and effective 